\title{
Concepções iniciais dos alunos do oitavo ano do ensino fundamental sobre a fosfoetanolamina
}

\section{RESUMO}

Este artigo relata as concepções iniciais dos alunos de uma turma de 8o ano do ensino fundamental de uma escola municipal da região sul de Mato Grosso do Sul sobre duas perguntas: Você é contra ou a favor da liberação da pílula do câncer? Por quê; Quais os meios de comunicação que você utiliza para se informar? Para a reunião dos dados foram selecionados fragmentos das respostas dos alunos e analisados à luz da perspectiva CiênciaTecnologia-Sociedade-Ambiente (CTSA). Por meio da investigação das concepções prévias dos alunos sobre a (QSC) fosfoetanolamina, verificou-se que os alunos obtêm informações pelos meios de comunicação de maneira fragmentada e descontextualizada. Isso vem fortalecer a importância de organizar o ensino pautado na perspectiva CTSA no intento de formar cidadãos críticos, que saibam interpretar as implicações do desenvolvimento científico e tecnológico na sociedade e sejam capazes de tomar decisões para o bem comum.

PALAVRAS-CHAVE: Perspectiva CTSA. Questões Sociocientíficas. Concepções prévias. 


\section{INTRODUÇÃO}

Atualmente, pela velocidade com que as informações se propagam através dos meios multimidiáticos, uma variedade de notícias tem atingido o cotidiano da população de forma geral, porém de forma fragmentada, descontextualizada e vazia de seus valores éticos e morais que auxiliam no processo de enculturação científica da sociedade. Isso recai, portanto, à escola, e principalmente ao ensino de ciências, o qual recebe diariamente uma carga de informações abrangendo o desenvolvimento científico e tecnológico que precisam ser problematizados para propiciar aos alunos a formação de opiniões concisas.

Perante este contexto, parece que se pode afirmar que a disseminação de notícias advindas dos meios de comunicação contribui para um processo semiformativo (IOP, 2009), no qual os alunos se habituam ao pensamento pronto propiciado pelas leituras que privilegiam interesses particulares de minorias e dificultam a compreensão dos limites e as relações benefícios/malefícios da ciência e da tecnologia (RATCLIFFE; GRACE, 2003).

Nesse sentindo, a globalização propiciou uma "inversão no fluxo do conhecimento" (CHASSOT, 2003, p. 90), uma vez que a escola recebe uma invasão de informações externas, repercutidas na maioria das vezes pelos alunos, chamados de "geração Y", que possuem livre acesso a essas informações. Por outro lado, a escola ainda vive diante do desafio de estabelecer aos componentes curriculares das Ciências Naturais os aspectos ontológicos e epistemológicos da ciência, no intento de se trabalhar em sala de aula as complexas e dinâmicas relações entre a Ciência, tecnologia, Sociedade e Ambiente (CTSA).

Diante deste cenário, uma das propostas é adotar metodologias diferenciadas que resultem em atividades de cunho argumentativo através de situaçõesproblema sob a influência das discussões CTSA, cujo objetivo seja direcionado à compreensão do desenvolvimento científico e tecnológico nos vários feitios que Ihes são apresentados, e, a partir daí, possam elaborar suas posições autônomas a seu respeito, ou seja, pretende-se com a perspectiva CTSA que os alunos sejam alfabetizados cientificamente. Mas, como organizar o Ensino de Ciências de maneira a contemplar os pressupostos CTSA e possibilitar uma formação crítica dos alunos sobre os avanços científicos e tecnológicos polêmicos divulgados pela mídia?

Uma alternativa para estudo de temas polêmicos que envolvem a ciência e a tecnologia e que causam divergência na opinião pública seria por meio da abordagem das controvérsias sociocientíficas. As controvérsias, também conhecidas como questões sociocientíficas (QSC), podem contribuir para esclarecimento e discussão de temas polêmicos, ao proporcionar estratégias de ensino com foco em situações-problema a nível local, nacional ou global e que afetam direta ou indiretamente a sociedade. A utilização de QSC nas aulas de ciências possibilita abordar aspectos políticos, econômicos, sociais, éticos, ambientais, entre outros relacionados à ciência e à tecnologia (C\&T) (LEVINSON, 2001; VIEIRA; BAZZO, 2007; GALVÃO; REIS, 2008).

Considerando essa mesma perspectiva, Krasilchik (1985, p. 8) defende uma educação científica que permita o envolvimento com temas que promovam julgamentos e formação de opiniões: "Além de propiciar conhecimentos para compreender os fenômenos da natureza, as disciplinas científicas devem 
desenvolver a capacidade dos alunos para assumirem posições face aos problemas controvertidos e agirem no sentido de resolvê-los". Além disso, o ensino pautado nas QSC coopera para a desmitificação das ideias distorcidas da ciência como neutra, livre de interesses e altruísta, promovendo a participação dos alunos nas discussões decorrentes das interações entre Ciência/Tecnologia/Sociedade/Ambiente (VIEIRA; BAZZO, 2007; PAIVA et al., 2013).

Pedretti (2003) aponta as questões sociocientíficas como vantajosas ao organizar o saber científico e explorar a perspectiva CTSA. Reforçando essa concepção, Zeidler e Keefer (2003) argumentam:

As questões sociocientíficas revelam-se úteis na transformação das aulas de ciências num "micro-cosmos social" promotor do desenvolvimento holístico dos alunos nos domínios cognitivo, social, moral, ético e emocional (ZEIDLER; KEEFER, 2003, p. 21, tradução nossa).

Por outro lado, embora este tipo de questão pareça ser potencial para levar os estudantes a conhecerem outras facetas sobre os avanços da ciência e da tecnologia, estudos revelam que estas atividades não constituem uma prática comum nas aulas de ciências (LOPES, 2010).

Sobre esse aspecto, Ratcliffe e Grace (2003) apontam algumas indicações ligadas ao currículo escolar que podem dificultar o enfoque das questões sociocientíficas nas escolas, tais como: a natureza do currículo escolar que nem sempre oportuniza a inclusão de controvérsias; a natureza multifacetada das questões sociocientíficas as quais o professor deve-se encontrar preparado para discutir seus valores e saber lidar com opiniões divergentes; seleção de estratégias de aprendizagem e de avaliação adequadas e, por último e não menos importante, a (falta de) habilidade pedagógica do professor.

Porém, qual a maneira mais propícia de se iniciar o estudo de uma QSC no Ensino de Ciências?

Para responder a esta pergunta, recorremos às concepções construtivistas que defendem a utilização dos conhecimentos prévios dos alunos no processo de ensino-aprendizagem. Esses conhecimentos prévios possibilitam conhecer as necessidades, interesses e dificuldades dos educandos sobre o tema e, portanto, auxiliam na organização do ensino por meio da seleção de conteúdos, metodologias e recursos mais adequados à realidade evidenciada (CASTRO; BEJARANO, 2012), pois, segundo essa concepção, uma aprendizagem só será significativa "quando o aluno for capaz de estabelecer relações coerentes entre o que já sabe e o novo conhecimento que lhe está sendo apresentado" (FREITASFILHO; CELESTINO, 2010, p. 188).

[...] Desta maneira, as concepções prévias podem ser tomadas como ponto de partida para a construção de novos conhecimentos. Assim sendo, o papel do indivíduo/estudante é o de construtor de seus conhecimentos a partir de seus interesses, que o conduz à ação no sentido de tomar para si um dado objeto. Este, o objeto, não é, de fato, puro, ou seja, é sempre o resultado de alguma interpretação do sujeito (FREITAS-FILHO; CELESTINO, 2010, p. 188).

Diante dessas perspectivas, este artigo apresenta os resultados iniciais de uma pesquisa de mestrado profissional, desenvolvida no contexto dos anos finais do Ensino Fundamental, cujo objetivo é analisar se a organização do ensino de 
ciências, pautada na fosfoetanolamina como questão sociocientífica, pode contribuir para os processos de ensino e de aprendizagem. Contudo, os resultados aqui apresentados referem-se à investigação das concepções iniciais dos alunos sobre a controvérsia fosfoetanolamina e as influências dos meios de comunicação na formação de suas opiniões.

\section{METODOLOGIA}

Esta pesquisa foi desenvolvida com 30 alunos, com idade entre 13 e 14 anos, de uma turma de oitavo ano do Ensino Fundamental, de uma escola municipal da região sul de Mato Grosso do Sul, durante o ano de 2016, e representa o recorte de uma investigação mais abrangente.

A fosfoetanolamina como questão sociocientífica foi escolhida para a realização da investigação das concepções iniciais dos estudantes, neste trabalho, e, posteriormente, para a sua problematização no contexto escolar, por entender que se trata de uma temática relevante ao processo de formação crítica dos educandos, além de contemplar a relação entre ciência-tecnologia-sociedade e ambiente, também poderá favorecer o desenvolvimento de capacidades e atitudes necessárias ao exercício da cidadania e ao convívio social.

Para a investigação das concepções iniciais dos alunos acerca da fosfoetanolamina, conhecida popularmente como "pílula do câncer", bem como conhecer os meios de comunicação mais acessíveis aos alunos que podem influenciar na obtenção de informações sobre a controvérsia, os alunos foram submetidos a duas perguntas: Você é contra ou a favor da liberação da pílula do câncer? Por quê?; Quais os meios de comunicação que você utiliza para se informar?

Os sujeitos envolvidos na pesquisa tiveram uma hora-aula para refletirem e responderem aos questionamentos, sendo que suas respostas foram registradas de forma descritiva, individual e sem acesso a materiais para consulta. Dessa maneira a pesquisa assume caráter qualitativo e descritivo por levar em consideração as opiniões com base nas experiências pessoais de cada aluno. Conforme complementa Bernardo (2013, p. 931), "a pesquisa se configura como do tipo descritiva, onde a palavra deve estar intimamente ligada ao seu contexto, já que estamos interessados no significado que os sujeitos atribuem ao que lhes é apresentado".

Para a reunião dos dados foram selecionados fragmentos das respostas dos alunos e analisados à luz da perspectiva CTSA. Em relação à escolha dos fragmentos, levou-se em consideração a heterogeneidade dos argumentos apresentados pelos alunos. Os trechos foram destacados em itálico no texto e, para garantir o anonimato das informações, os alunos participantes do estudo foram identificados pela primeira letra correspondente a inicial de seus nomes, seguido pelo seu número de chamada.

\section{RESULTADOS E DISCUSSÃO}

Quando os alunos participantes da pesquisa foram questionados se são contra ou a favor da liberação da pílula do câncer, $36 \%$ (11 alunos) se posicionaram a favor 
da sua liberação, entretanto, suas justificativas denotaram a ausência de análise crítica sobre os vários aspectos que abarcam esta controvérsia.

J18: "A favor porque os cientistas acreditam que essa pílula do câncer poderia curar as pessoas que tem câncer".

No trecho transcrito acima, observa-se a presença de imagens distorcidas da ciência, como: salvacionista, superior às crenças e inquestionável. A propagação destas imagens deve-se, muitas vezes, ao fato dos sujeitos não conhecerem as interferências negativas dos avanços científicos e tecnológicos no seu cotidiano, portanto, ficam susceptíveis a influências na escolha dos medicamentos indicados por profissionais ou por meio da alienação de marcas pela mídia. Neste aspecto, a perspectiva CTSA, ao ser a base para organização do ensino de ciências, vem contribuir para desmistificação das imagens distorcidas da ciência ao considerar um ensino que aborde os aspectos sociais, políticos, culturais, éticos/morais e econômicos de assuntos polêmicos, como a fosfoetanolamina, contribuindo assim para uma visão crítica da C\&T (SADLER, 2004; VIEIRA; BAZZO, 2007; GALVÃO; REIS, 2008).

Analisando outros fragmentos das falas dos alunos, o mito em torno da ciência como promotora de tecnologias que só trazem benefícios à sociedade se fortalece:

D11: "Sim. Porque se é uma pilula é porque é para a saúde".

L23: "Eu sou a favor porque se fabrica, essa pílula pode curar as pessoas que tem câncer".

Isso vem fortalecer a importância de um ensino que possibilita a análise crítica da relação entre CTSA, a fim de auxiliar os sujeitos na avaliação dos avanços científicos e tecnológicos presentes em seu cotidiano, como sugere Sasseron e Carvalho (2008). Logo, segundo Lopes e Carvalho (2012, p. 273), é necessário se pensar em um ensino que atenta às implicações da ciência, cujos "[...] produtos tecnológicos são cada vez mais difundidos, sem a reflexão necessária sobre suas relações custo/benefício e de risco".

Nas respostas dos alunos, a ideia da pílula do câncer, a fosfoetanolamina, como alternativa aos tratamentos convencionais da doença também é revelada, como pode ser observada nas transcrições abaixo:

A2: "sim, pois essa pílula vai ajudar a controlar a doença e fazendo com que a pessoa viva mais tempo".

G17: "Sim. Porque isso pode sauvar as pessoas".

C4: "Sou a favor porque ela pode ajudar a acabar com o câncer. Ela pode fazer com que você viva normalmente com o câncer. Ela é um tipo tratamento para o câncer".

Podemos fazer um paralelo entre as falas acima com a maneira como a mídia tem divulgado as notícias, as quais são, na maioria das vezes, fragmentadas e descontextualizadas. Apesar de $73 \%$ dos alunos (22 alunos) responderem ter acesso às notícias por meio de jornais na TV, percebe-se que sua abordagem não tem permitido que estes reconheçam os interesses particulares, econômicos e políticos que se encontram por trás dos avanços da C\&T, assim como seus riscos, limites, implicações e aplicações no seu cotidiano. 
Entre os alunos que se manifestaram favoráveis à utilização da pílula do câncer, alguns demonstraram ter conhecimentos de base científica sobre sintomas e tratamentos da doença, porém, suas opiniões não denotaram senso crítico em torno desta polêmica:

S30: sou a favor por que quando a célula concerosa começa a se reproduzir muito e não para comesa a formar o câncer. Se for o benigno não precisa fazer sirurgia e se for o maligno pode levar a morte.

L22: sim, pois ela pode evitar a doença ou combater os sintomas do câncer como cair o cabelo, porque tem vários tipos de câncer, pois sou a favor sim porque pode ajudar a combater a doença e quem estiver doente pode sarar.

Nesta perspectiva, Pedrancini (2008, p. 143) destaca a importância da escola para que, por meio dos conteúdos científicos estudados, os alunos compreendam as discussões que emergem do cotidiano:

\begin{abstract}
Embora no meio científico ocorram discussões dessa natureza - mesmo que apresentem explicações e fundamentações divergentes - o que chega aos alunos são informações aligeiradas, "comandos" insuficientes para garantir que defendam posicionamentos pautando- se em conhecimentos sistematizados.
\end{abstract}

Em relação às opiniões divergentes, $23 \%$ (7 alunos) se manifestaram contra a liberação da pílula do câncer (fosfoetanolamina) pela substância não ter passado pelos devidos testes clínicos ou por apresentarem dificuldades na interpretação do conceito "pílula":

D12: "Contra. Porque ainda não foi provado se tem eficassea contra a doença".

F15: "Contra porque não sei o que é pilula".

F33: "Contra porque a pílula pode matar pouco a pouco".

Observando a fala do aluno D12, compreendemos que sua opinião seja mais crítica em relação à fosfoetanolamina, pois apresenta uma análise mais cautelosa a respeito do tema, convergindo com a opinião da Agência Nacional de Vigilância Sanitária (ANVISA), a qual destaca que essa substância precisa ser submetida a testes clínicos em humanos antes de ser liberada para produção, comercialização e uso:

[...] não há nenhuma avaliação de qualidade, segurança e eficácia realizada pela Agência, portanto a Anvisa não tem como reconhecer, por absoluta falta de dados científicos, a suposta eficácia da fosfoetanolamina para o tratamento do câncer, ou seja, os seus efeitos são totalmente desconhecidos. Alertamos que todos os tipos de tratamentos devem ser fundamentados em resultados de estudos cientificamente comprovados (ANVISA, 2015, p. 3).

Por outro lado, apesar do aluno D12 apresentar uma visão mais crítica acerca do assunto, observou-se que não o compreende em sua totalidade. Diante desse cenário, percebe-se a relevância de um ensino de ciências que possibilite a discussão crítica e reflexiva acerca do contexto científico-tecnológico. (LEVINSON, 2001; JIMÉNEZ-ALEIXANDRE, 2005).

Um dado preocupante desta pesquisa sobre a liberação da chamada "pílula do câncer" percorre sobre o fato de $40 \%$ dos alunos (12 alunos), ou seja, quase metade dos participantes relatarem nunca ter ouvido falar sobre esta substância: 
G16: "Eu nunca ouvi falar sobre a pílula do câncer por isso não sou nem a favor nem contra".

L27: "Eu não sei o que é a pílula do câncer, eu nunca ouvi falar da pílula do câncer. O que será a pílula do câncer, será que é uma doença sem cura?".

Apesar desta polêmica ser tratada com frequência pela mídia, estas respostas demostram que os alunos não acompanham meios de comunicação que divulgam notícias de ciência, tecnologia e saúde. De acordo com as suas respostas, os meios de comunicação que manipulam são utilizados da seguinte forma: 56\% (17 alunos) participantes utilizam o programa whatsapp e 53\% (16 alunos) facebook, porém, como registrado pelos próprios alunos, o que Ihes chamam atenção nestes meios de comunicação é a possibilidade de bate-papo com os colegas, promulgando uma falta de interesse por assuntos que envolvam ciência e tecnologia.

Outro veículo de informação contemplado nas falas dos alunos ( $33 \%$ ou 10 alunos) foi o livro didático. Estes alunos destacaram que a maior parte das notícias que recebem está presente no material didático adotado pela escola. Essa constatação demanda que esses materiais didáticos abordem as informações sobre temas atuais de relevância social e de forma a abranger sua totalidade. Para tanto, ao professor é destinada a função de selecionar o material didático que agrupa informações mais completas sobre assuntos discutidos em sala de aula. Além disso, para Rosa e colaboradores $(2007$, p. 365$)$ a função do professor recai em...

[...] trazer para a sala de aula um conhecimento em voga, construído socialmente e que deverá despertar no aluno o interesse pelo saber. Para isso, o uso de metodologias diferenciadas, de estratégias de ensino voltadas à construção e ao questionamento do saber deve constituir a essência das suas atividades pedagógicas. É necessário incentivar os estudantes a compreenderem o conhecimento.

De acordo com este levantamento das concepções iniciais dos estudantes sobre a considerada "pílula do câncer" (fosfoetanolamina), observamos que o emprego da perspectiva CTSA, por meio de questões sociocientíficas, para a organização das aulas de ciências pode permitir preencher as lacunas que os alunos apresentaram aqui sobre os temas que são divulgados diariamente pela mídia, isto é, podem promover uma visão mais crítica e reflexiva da C\&T presente em nosso cotidiano.

\section{CONSIDERAÇÕES FINAIS}

Analisando as concepções iniciais dos alunos sobre a controvérsia fosfoetanolamina, conhecida por eles como a "pílula do câncer", 36\% (11 alunos) se posicionaram a favor de sua liberação, porém suas respostas demonstraram pouco conhecimento a respeito das implicações desta substância para saúde pública. Por outro lado, 23\% (7 alunos) se manifestaram contra a liberação da pílula do câncer (fosfoetanolamina), apresentando justificativas como irregularidades na liberação da droga ou por reconhecerem que não possuem conhecimento 
evidenciando que, apesar de estarem conectados via multimídias com várias notícias globais, apresentam em si uma falta de interesse por notícias em relação à ciência, tecnologia e saúde pública.

A investigação das concepções prévias dos alunos sobre a fosfoetanolamina, aqui apresentada, nos permitiu observar a importância de se considerar um ensino organizado por meio da perspectiva CTSA, no intento de formar cidadãos críticos, que saibam analisar os riscos, limites, implicações e aplicações do desenvolvimento científico e tecnológico na sociedade, e sejam capazes de tomar decisões para o bem comum.

Sendo assim, as questões ou controvérsias sociocientíficas apresentam-se como uma abordagem potencial no ensino de ciências, com enfoque CTSA, por abordarem aspectos sociais, políticos, econômicos, culturais e morais que, ao serem explorados, permitem uma visão holística do assunto estudado e, portanto, subsidia na formação de opiniões.

Outro ponto contundente desta pesquisa se detém sobre as influências dos meios de comunicação na formação de opiniões dos alunos. Essas informações estão chegando de maneira fragmentada e descontextualizada à sociedade, dificultando sua interpretação e relação com os conteúdos científicos abordados no currículo escolar.

Assim, é dever da escola, e de forma mais explícita do professor como mediador pedagógico, problematizar essas controvérsias contemporâneas em sala de aula e discutir a sua relação com contexto social dos educandos, auxiliando na formação de cidadãos críticos. 


\title{
STUDENTS' FROM 8th GRADE OF ELEMENTARY SCHOOL INITIAL CONCEPTIONS ABOUT PHOSPHOETHANOLAMINE
}

\begin{abstract}
This article presents the students' initial conceptions about the controversial topic phosphoethanolamine and the media influence in forming students' opinions. Therefore, we selected a group of students from 8th grade of an elementary school of a municipal school from the south region of Mato Grosso do Sul State, and the students answered two questions: Are you for or against the release of cancer pill? Why?; What media do you use to get information? For data grouping, fragments of students' answers were selected and analyzed in the Science-Technology-Society-Environment perspective (STSE). Thus, the research takes qualitative and descriptive character by taking into account the views based on personal experiences of each student. Through the investigation of students' previous conceptions on phosphoethanolamine social-scientific questions, it was found that the students get information by the media in a fragmented and decontextualized way. This strengthens the importance of organizing education guided in STSE perspective in an attempt to form critical citizens who know how to interpret the implications of scientific and technological development in society and be able to make decisions for the common good.
\end{abstract}

KEYWORDS: STSE Perspective. Socio-scientific issues. Previous conceptions. 


\section{Agradecimentos}

Ao Programa Institucional de Bolsas aos Alunos de pós-graduação da UEMS PIBAP.

\section{REFERÊNCIAS}

BERNARDO, J. R. R. Abordagem de questões sociocientíficas nas aulas de física: as usinas nucleares em debate. In: IX CONGRESO INTERNACIONAL SOBRE INVESTIGACIÓN EN DIDÁCTICA DE LAS CIENCIAS, Girona. Anais...Girona: España, 2013. p. 9-12. Disponível em:

<http://www.raco.cat/index.php/Ensenanza/article/viewFile/306281/396186>. Acesso em: 04 de Ago. 2016.

BRASIL. Agência de Vigilância Sanitária. Nota Técnica no56/2015/SUMED/ANVISA. Superintendência de Medicamentos e Produtos Biológicos-SUMED/ANVISA, 2015. Disponível em: $<$ http://www.escoladaajuris.com.br/esm/images/arquivos/Material_Fosfoetanol amina/ANVISA_NOTA_TECNICA_56_2015fosfoetanolamina.pdf>. Acesso em: 04 de Ago. 2016.

CASTRO, D. R.; BEJARANO, N. R. R. O perfil de conhecimento sobre seres vivos pelos estudantes da COOPEC: uma ferramenta para planejar um ensino de ciências. Revista Ensaio. Belo Horizonte, v.14, n. 03, p. 261-274, 2012. Disponível em: <http://portal.fae.ufmg.br/seer/index.php/ensaio/article/view/547/1061>. Acesso em: 04 de Ago. 2016.

CHASSOT, A. Alfabetização científica: uma possibilidade para a inclusão social. Revista Brasileira de Educação. Universidade de vale do Rio dos Sinos, n. 22, p. 89-99, 2003. Disponível em: <http://www.scielo.br/pdf/\%0D/rbedu/n22/n22a09>. Acesso em: 04 de Ago. 2016.

FREITAS-FILHO, J. R.; CELESTINO, R. M. C. S. Investigação da construção do conceito de reação química a partir dos conhecimentos prévios e das interações sociais. Revista Ciências \& Cognição, Rio de Janeiro, v. 15 (1), p. 187-198, 2010. Disponível em: <http://pepsic.bvsalud.org/pdf/cc/v15n1/v15n1a15.pdf>. Acesso em: 04 de Ago. 2016. ciência através da discussão de controvérsias sociocientíficas. In: VIEIRA, R. M.; PEDROSA, M. A. F.; PAIXÃO, I. P.; MARTINS, A.; CAAMAÑO, V. A.; MARTÍN-DIAZ, M. J. (org.). Ciência-tecnologia-sociedade no ensino das ciências: Educação 
científica e desenvolvimento sustentável. Aveiro: Universidade de Aveiro, 2008. p. 131-135.

IOP, E. Formação cultural, semicultura e indústria cultural: contribuições de Adorno sobre a emancipação. REP - Revista Espaço Pedagógico, Passo Fundo, v. 16, n. 2, p. 20-33, jul./dez. 2009. Disponível em:

$<$ https://scholar.google.com.br/scholar?q=Forma\%C3\%A7\%C3\%A3o+cultural\%2C +semicultura+e+ind\%C3\%BAstria+cultural\%3A+contribui\%C3\%A7\%C3\%B5es+de+ Adorno+sobre+a+emancipa\%C3\%A7\%C3\%A3o\&btnG=\&hl=ptBR\&as_sdt=0\%2C5>. Acesso em: 04 de Ago. 2016.

JIMENEZ-ALEIXANDRE, M. P. A argumentação sobre questões sócio-científicas: processos de construção e justificação do conhecimento na aula. In: V Encontro Nacional de Pesquisa em Ensino de Ciências, Bauru. Anais... Abrapec, 2005. Disponível em: <http://www.nutes.ufrj.br/abrapec/venpec/conteudo/oraltitulo.htm>. Acesso em: 04 de Ago. 2-16.

KRAILCHIK, M. Ensinando Ciências para assumir responsabilidades sociais. Revista de Ensino de Ciências, v. 14, p. 8-10, 1985.

LEVINSON, R. As ciências ou as humanidades: quem deve ensinar as controvérsias em ciência? In: PRÓ-POSIÇÕES, Periódicos: Sistema da Biblioteca da Unicamp, v.12, n. 1 (34), p. 62-72. 2001.

LOPES, N. C. Aspectos formativos da experiência com questões sociocientíficas no ensino de ciências sob uma perspectiva crítica. Bauru, 230 p., 2010. Dissertação (Mestrado)- Universidade Estadual de São Paulo.

LOPES, N. C.; CARVALHO, W. L. P. Aspectos formativos da experiência com questões sociocientíficas no ensino de ciências sob uma perspectiva crítica. In: CARVALHO, L. M.; CARVALHO, W. L. P. (org.). Formação de Professores "Questões Sociocientíficas no Ensino de Ciências". São Paulo: Escrituras Editora, 2012. p. 271-292.

PAIVA, C. L.; ZANI, L. D.; DUARTE, I. D.; SILVA, M. A. J. Uso indiscriminado de antibióticos e superbactérias KPC: CTS controverso no ensino de biologia. Revista Eletrônica Debates em Educação Científica e Tecnológica, ISBN: 2236-2150, v. 03, n. 01, p. 32 - 40, Junho de 2013. Disponível em: <http://ojs.ifes.edu.br/index.php/dect/article/viewFile/16/97>. Acesso em: 04 de Ago. 2016. alunos do ensino médio sobre transgênicos. Ciência \& Educação, v. 14, n. 1, p. 
135-146, 2008. Disponível em: $<$ https://dialnet.unirioja.es/servlet/articulo?codigo=5274284>. Acesso em: $04 \mathrm{de}$ Ago. 2016.

RATCLIFFE, M.; GRACE, M. Science Education for citizenship: Teaching socioscientific issues. USA: Open University Press, 181 p. 2003.

ROSA, C. W. et al. Ensino de física nas séries iniciais: concepções da prática docente. Investigações em Ensino de Ciências, v. 12(3), p. 357-368, 2007. Disponível em: <http://physika.info/physika/srozane/Artigo_01.pdf> Acesso em: 04 de Ago. 2016.

SADLER, T. D. Moral sensivity and its contribution to the resolution of sócioscientificissues. Journal of Moral Education, v.33, n.3, p. 239-358, 2004.

SASSERON, L. H.; CARVALHO, A. M. P. Almejando a alfabetização científica no ensino fundamental: a proposição e a procura de indicadores do processo. Investigações em Ensino de Ciências, v.13(3), p.333-352, 2008. Disponível em: <http://s3.amazonaws.com/academia.edu.documents/31252605/Almejando_a_ alfabetizacao_cientifica_no_Ensino_Fundamental_a_proposicao_e_a_procura_ de_indicadores_do_processo.pdf?AWSAccessKeyId=AKIAJ56TQJRTWSMTNPEA\&E xpires $=1470349393 \&$ Signature $=0 X 7 f 4 \mathrm{HndLTtMJikOsRMq6Muw \% 2FMg \% 3D \& resp}$ onsecontentdisposition=inline\%3B\%20filename\%3DAlmejando_a_alfabetizacao_ cientifica_no.pdf>. Acesso em: 04 de Ago. 2016.

VIEIRA, K. R. C. F.; BAZZO, W. A. Discussões acerca do aquecimento global: uma proposta CTS para abordar esse tema controverso em sala de aula. Ciência \& Ensino, v. 1, número especial, p. 1-12, 2007. Disponível em:

$<$ https://scholar.google.com.br/scholar?q=Discuss\%C3\%B5es+acerca+do+aqueci mento+global\%3A+uma+proposta+CTS+para+abordar+esse+tema+controverso+e $\mathrm{m}+$ sala + de+aula.+\&btnG=\&hl=pt-BR\&as_sdt=0\%2C5>Acesso em: 04 de Ago. 20

DOI: 10.3895/rbect.v10n1.5723

Como citar: MOREIRA, C. S.; PEDRANCINI, V. D. Concepções iniciais dos alunos do oitavo ano do ensino fundamental sobre a fosfoetanolamina. Revista Brasileira de Ensino de Ciência e Tecnologia, v. 10, n. 1 , 2017. Disponível em: <https://revistas.utfpr.edu.br/rbect/article/view/5723>. Acesso em: xxx.

Direito autoral: Este artigo está licenciado sob os termos da Licença Creative Commons-Atribuição 4.0 Internacional. 